\title{
scripted
}

Volume 13, Issue 2, August 2016

\section{CONFERENCE REPORT: THE INTERNATIONAL NETWORK ON FEMINIST APPROACHES TO BIOETHICS WORLD CONGRESS 2016}

\author{
Catriona McMillan ${ }^{1}$ and Agomoni Ganguli Mitra ${ }^{2}$
}

DOI: $10.2966 /$ scrip.130216.197

\section{(c) (i) $\Theta$}

(C) Catriona McMillan and Agomoni Ganguli Mitra 2016. This work is licensed under a Creative Commons Licence. Please click on the link to read the terms and conditions.

\footnotetext{
${ }^{1}$ PhD Candidate and Member of Liminal Spaces Project, School of Law, University of Edinburgh.

${ }^{2}$ Research Associate in Liminal Spaces Project, School of Law, University of Edinburgh.
} 
The 2016 International Network on Feminist Approaches to Bioethics (FAB) World Congress was once again a testimony FAB's strong commitment to academic rigour. It was also a testimony, however, to pushing boundaries and unsettling paradigms in bioethics scholarship, health, wellbeing, equality, justice, gender, culture, politics and society, all within a collegial and supportive atmosphere. This year, the $11^{\text {th }} \mathrm{FAB}$ conference took place in the city of Edinburgh, Scotland, with over 100 delegates from around the world in attendance. FAB has a long-standing association with the International Association of Bioethics (IAB), and took place on the $13^{\text {th }}$ and $14^{\text {th }}$ of June, before their crossover session on the $15^{\text {th }}$ of June that coincided with the commencement of IAB2016. ${ }^{1}$ In this short Conference Report, we discuss several highlights of the FAB World Congress.

In her opening keynote, entitled "Why Gender Sensitivity Matters and How it can be used for Public Health," Kate Hunt argued for the need to challenge dominant paradigms around gender and health that are often built on myths about, for example, help-seeking behaviour differentials between genders. Hunt pointed out the drawbacks of existing studies suggesting that men are more reluctant to access health care and how this affect the health of both men and women. Providing the example of a public health intervention with men based on a common passion for local football, she argued that public health "...ignores gender sensitivity and gender sensitization at its own peril, because the industry does not." Illustrating the remarkable agility with which the tobacco industry has gotten both women and men to smoke, she pointed out how public health interventions on the other hand, had often failed to be so adaptable and hence as effective.

An interesting question that arose from Hunt's examples, and one that was taken up by IAB President Angela Ballantyne was whether, in taking on gender-based norms and preferences as basis for public health interventions, they might in fact reinforce gender stereotypes.

Over the next two days, the delegates were treated to a wide array of bioethics-related topics, ranging from theoretical and analytical papers to ones based on applied, or empirical, social and anthropological work. One of the aspects of this year's FAB that was particularly interesting was the sheer variety and extent of global representation, both in terms of speakers and topics addressed.

Echoing the theme of global bioethics that was featured prominently at this year's $\mathrm{IAB},{ }^{2}$ one of the early FAB sessions, entitled "Around the World," featured speakers from a variety of disciplines and geographic backgrounds. Shathi Samara Ragaven and Laurel Baldwin Ragaven, a mother-daughter feature fitting of the FAB banner, critiqued patient safety approaches, especially the use of universal checklist through a feminist and contextual lens, and from the perspective of the realities of low-income countries. "How important is a checklist for a nurse when there is no running water or sterile gloves?", they asked. Moving on from the context of South Africa, Anna Gotlib spoke about the tensions between what is often perceived as "foreign

\footnotetext{
${ }^{1}$ For a report on IAB2016, see in this issue ES Dove et al, "Conference Report: $13^{\text {th }}$ World Congress of the International Association of Bioethics, Edinburgh 14-17 June 2016 (IAB2016)" 13 SCRIPTed.

${ }^{2}$ International Association of Bioethics World Congress 2016, available at http://iab2016.com/ (last accessed 09 Aug 2016).
} 
neoliberal narratives" on the discourse around women's reproductive rights and health in post-Soviet Russia. ${ }^{3}$ Given the resistance the social and institutional resistance to feminist discourse, she illustrated the need to adapt feminist politics to local ways and the need for a coalition between inside and outside actors if women's interests are to be adequately addressed. Global concerns were taken up in several of the rapid pitches. To highlight a few examples among many: Rhyddhi Chakraborty offered capabilities-based insights to how the avian flu outbreak in 2006 affected women disproportionately because of the preponderance of backyard poultry farming, a sector that often involves more women, ${ }^{4}$ while Nicole Fice spoke of the various inequalities faced by indigenous Canadians compared to the rest of the population. ${ }^{5}$ Offering a group egalitarian lens, she suggested that purely individualistic measures of inequality were not enough to highlight the institutional oppression faced by certain groups and social positions.

In a different strand examining the relationship between gender, health and diets, two different speakers, Alison Reiheld and Taryn Knox, questioned the disease-status of obesity, and the difficulties and discriminations associated with this status and the resulting public health interventions. Their presentations also examined the burden on women in interventions that focus on healthy mums and families, the over-importance on BMI as an adequate measure of health (patients who fail to lose weight are viewed as non-compliant and lazy), and how the fight against obesity has worked towards reinforcing problematic gender norms in men and women. ${ }^{6}$

Another dominant thread amongst this year's FAB contributions was the issues and tensions associated with the early and later stages of human life. In a strand exploring the relationship between older people, identity and personhood, Françoise Baylis drew upon the novel Still Alice, ${ }^{7}$ to consider the ways in which relational theory should "work harder" to provide support and experience of the "self" for those with degenerative mental diseases such as Alzheimer's and dementia. ${ }^{4}$ Meanwhile, in another presentation, Heike Felzman discussed the potential relational impact of the use of assistive robots to provide care for older persons with dementia. ${ }^{5}$ Angel and Voula Petropanagos provided a narrative account of a "migrant" personal support worker who moves between dementia care settings, and argued that this account reveals tension between those settings and sheds light on the meaning and nature of care relationships between dementia patients and caregivers. ${ }^{6}$

\footnotetext{
3 Anna Gotlib: “' The sick man of Europe': women's healthcare regulation as surrogate for Russia's public health disaster."

${ }^{4}$ Rhyddhi Chakraborty: "Capabilities approach, backyard poultry farming and Indian pandemic plan."

${ }^{5}$ Nicole Fice: "Health care inequalities faced by indigenous Canadians."

${ }^{6}$ Alison Reiheld and Taryn Knox "Not the parity we want: disordered eating and normative appetites in North American men and women."

${ }^{7}$ L Genova, Still Alice (Bloomington, IN: iUniverse, 2007).

${ }^{4}$ Françoise Baylis: "'She is who she is': Alzheimer's and identity."

${ }^{5}$ Heike Felzman: 'Assistive care robots for older persons with dementia: challenges for the web of care'

6 Angel Petropanagos and Voula Petropanagos: "Frozen hope: understanding the role of hope in fertility preservation."
} 
In a panel session on "Pregnant Women and Health Research: Challenges and Solutions," Angela Ballantyne, Françoise Baylis, and Carolyn Ellis drew on law, empirical cases, epistemology and ethics to explore the supposed barriers to health research on pregnant women. Here it was first argued that pregnant women should be presumed as eligible research participants. While pregnant women are often precluded from partaking fully in several phases of clinical research trials, they are routinely included in "trials of one" under the guise of therapy. It was argued that the latter should not be the case, and an interesting rationale was provided for presumptive eligibility, including qualitative research that showed that pregnant women want to be able to participate in research that might help others. The next three presentations then went on to prescribe how this might be put into practice, drawing on an empirical case from New Zealand, the ethical issues associated with maternal gene transfer, and lastly an exploration of the challenges to inclusion of pregnant women in clinical trials. It was argued that as a result of insufficient guidance on national and international research guidelines, a culture of reluctance to approve clinical trials involving research on pregnant women has grown.

A prevalent sub-stream of gender and reproduction within FAB was that of human reproductive technologies. In a dedicated session, Clare Horner explored the ethical issues in perimortem oocyte retrieval ${ }^{7}$ and Lisa Campo-Engelstein examined how the US media portray social egg freezing. ${ }^{8}$ Maru Mormina later provided thoughtprovoking analysis on the question of whether taxpayers should fund assisted reproduction, and suggested that while ART is justifiable in some cases, the social value of adoption should be recaptured in order to balance society's obligations to those who are disadvantaged, and the rights of those who wish to have a family. ${ }^{9}$

In an inspiring and moving tribute to one of the early stalwarts of feminism in bioethics, the late Anne Donchin, ${ }^{10}$ Laura Purdy and Carolyn McLeod spoke effusively of Donchin's legacy on their own careers and work, as well as her legacy to the feminist bioethics community. This was followed by the announcement of the first Donchin-Holmes essay prize, awarded this year to Zohar Lederman for his essay entitled: "Families for Life... and Death. Family Presence During Resuscitation," in which he used a phenomenological account of relational autonomy to make a case for offering family members to be present during the resuscitation of patients.

The question of options, choices and refusals was then echoed in the afternoon sessions with among others, two very interesting and equally unsettling talks. Carey DeMichelis presented on the difficulties and perils of accommodating cultural preferences when it comes to adolescent treatment refusals, ${ }^{11}$ while Rachel Adams

\footnotetext{
7 Clare Horner: "Reproductive equality or objectification? Ethical issues in perimortem oocyte retrieval."

${ }^{8}$ Lisa Campo-Engelstein, Wendy Parker, Rohia Aziz, Shilpa Darivemula, and Jennifer Raffaele: "Freezing fertility or freezing false hope? A content analysis of the portrayal of social egg freezing in the US print media."

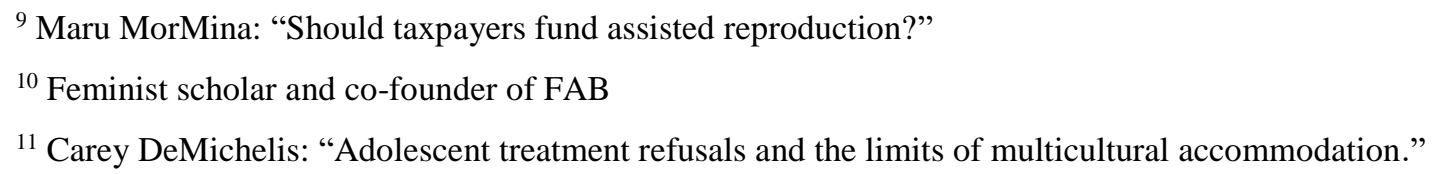


addressed the difficult challenges faced by junior doctors as a result of legal obligations such as mandatory reporting of female genital mutilation. ${ }^{12}$

The next day, the final event of FAB 2016 took place: the crossover plenary keynote, which ran jointly with IAB. This session highlighted the importance of social justice considerations in health, with presentations from Lisa Eckenwiler ${ }^{13}$ and Florencia Luna. ${ }^{14}$ Eckenwiler illustrated the importance of place in considerations of justice in public health, and as a crucial aspect to the social determinants of health. She called for a bio-centred egalitarianism that would recognise the importance of ethicalplacemaking for humans and their environment. With further attention to structural justice, Luna brought a gender lens to Zika as a public health and humanitarian crisis. The keynote speeches strongly echoed various themes from both conferences, illustrating how the complicated links between justice, gender, disease and the environment, as well as their associated policies, interact to enable and impede health and well-being.

Overall, FAB's main theme, "Feminist Perspectives and Public Health: Individuals, Communities, and the Public Good", was thoroughly explored by over 80 presentations from an international delegation on a number of fascinating sub-themes. The range of presentation formats, from five-minute rapid pitches, to presentations and panels, provided opportunity for varied and in-depth discussions of many of the feminist and gendered issues faced in bioethics today.

\footnotetext{
${ }^{12}$ Rachel Adams: “The legal and political construction of 'female genital mutilation' in the UK and its impact on the doctor-patient relationship... A feminist content analysis."

${ }^{13}$ Lisa Eckenwiler: "Ethical place making for health and health justice."

${ }^{14}$ Florencia Luna: "Women and (non) ethical places: the case of Zika."
} 